\title{
Denervated Muscle: Rate of Propagation and Effects of Manganese Ions and Glycerol on the Fibrillatory Activity of Frog Semitendinosus
}

\author{
Enrique LóPEZ \\ Departamento de Investigación, Instituto Nacional de Ortopedia, \\ S. S. A., México 14, D. F. Mexico
}

\begin{abstract}
Denervated frog's semitendinosus muscles were studied. Fibrillation potentials generate propagated spikes which are conducted at a rate similar to that calculated for innervated muscles. The twitch tension per unit area was similar in denervated and innervated single fibres; the average value corresponded with values reported in the literature for fibres stimulated at 125/sec. Manganese ions (1-3 mM), selectively inhibit fibrillation potentials and have no appreciable effect upon evoked spikes. $\mathrm{Mn}^{2+}$ also inhibits $(40-50 \%)$ the twitch responses and abolishes the resting tension of muscle fibres. The latter effects were observed in denervated as well as in innervated preparations when the fibres studied belonged to fascicles located at the site of entrance of the nerve. Disruption of the transverse tubular system by glycerol treatment does not interfere with the generation of fibrillation potentials, although the effects on twitching are similar to those reported in the literature. A possible mechanism is proposed to explain the generation of fibrillation potentials in frog denervated muscles.
\end{abstract}

The fibrillatory activity of the denervated semitendinosus muscle of the frog has been described in a previous paper (LóPEZ, 1978). It was mentioned, as a possibility to explain the poor tension development occasionally observed in that study, that fibrillation potentials might not give rise to propagated electrical activity. It was also considered that the transverse tubular system (TTS), a possible site of origin of the discrete depolarizations found in denervated mammalian muscles (Purves and SAKMANn, 1974; SMITH and TheslefF, 1976), could provide an explanation to the fact that, in the frog, it is possible to obtain spontaneous depolarizations, and repetitive firing, from any spot along the muscle length.

On these bases, the present study was aimed at obtaining further information related to the propagation of fibrillation potentials and inquiring further about the role the TTS may possibly play in the genesis of the electrical fibrillatory activity. The results obtained during the study are described in this paper.

Received for publication April 23, 1979 


\section{MATERIAL AND METHODS}

Local frogs (Rana pipiens, $N=120$ ) were used as experimental animals. Frogs were anesthetized with ether ( $5 \%$ aqueous solution) and operated on under a dissecting microscope. The innervation of both heads of the semitendinosus muscle ( $N$. descendans communis) was sectioned via a posterior approach at a site located between the ileo-fibularis, the ileo-femoralis and the pyriformis muscles, in the neighborhood of the septum gluteale. Denervated muscles were removed at variable intervals after the operation (12-60 days) and immersed in Ringer saline at room temperature $\left(20-22^{\circ} \mathrm{C}\right)$. All experiments were made on the ventral head; in most of the experiments, strips containing from 3 to about 20 fibres were used; in some cases, however, the study was made either on isolated single twitch fibres or on the whole ventral body. Strips and single fibres, unless otherwise stated in the text, were dissected from the region of entrance of the nerve into the muscle. The strips and the single fibres were transferred into a narrow channel (less than $0.3 \mathrm{ml}$ in capacity) carved at the bottom of the dissecting chamber. One of the tendons of the preparation was pinned down to a small well filled with bone wax, while the other was attached to a force transducer (Grass, FT 03C). The excess Ringer on top of the channel was sucked out. The saline in the channel could be replaced in a fraction of a second. Resting tension was applied by stretching the muscles to 1.2 times their slack length.

Fibrillation potentials were recorded by means of conventional $3 \mathrm{M}-\mathrm{KCl}$ microelectrodes, using standard intracellular recording techniques. In experiments using the whole muscle, potentials were recorded only from superficial cells. Tension was recorded on either paper or film. The force transducer was connected to an ink recorder oscilograph (Grass, Model 7) through a direct-coupled preamplifer (7P1); the signal was monitored on the oscilloscope (Tektronix 502). The oscilloscope traces were filmed with a Kymographic camera (Grass, C4).

Electrical stimulation, when desired, consisted of square pulses, $5 \mathrm{msec}$ in duration and various strengths, provided by a Grass S8 stimulator, applied to the surface of the fibres through a glass capillary tube filled with Agar-Ringer.

The conduction velocity was calculated from the action potentials recorded by two microelectrodes inserted in the same fibre. The latency between the action potentials was measured from an enlarged $(5-10 \times)$ projection of the recordings.

Measurements of the diameter of single fibres were made according to a modified microphotographic technique (REUBEN et al., 1964), with the assistance of a calibrated ocular micrometer. Only one spot of the single fibres was measured.

The composition of the solution used was as follows (in $\mathrm{mm}$ ).

Ringer saline: $\mathrm{Na}^{+} 117.5 ; \mathrm{K}^{+} 2.5 ; \mathrm{Ca}^{2+} 1.8 ; \mathrm{Cl}^{-} 121 ; \mathrm{HCO}_{3}^{-} 2.5$.

Glycerol saline: same as above plus $400 \mathrm{~mm}$ glycerol.

Manganese saline: same as Ringer saline plus $\mathrm{MnCl}_{2}$ at a concentration between 0.5 and $3 \mathrm{~mm}$. 


\section{RESULTS}

\section{Propagation in the denervated muscle}

The experiments in which the denervated muscle fibres were impaled by two microelectrodes showed that fibrillation potentials give rise to propagated action potentials similar to those evoked by electrical stimulation.

Most of the experimental muscles were studied at a time after denervation at which the sole penetration of the electrode was enough to start a discharge. Thus, to introduce the second microelectrode it was necessary to wait for the membrane to repolarize after the end of the discharge provoked by the introduction of the first microelectrode. On occasion, the second microelectrode was introduced in a different fibre; one adjacent to that penetrated by the first impalement. This situation could be recognized by either one of the following findings: a) absence of potentials in one of the beams, when only one of the fibres was discharging; b) lack of sustained synchronization, when the two fibres discharged simultaneously.

Several sequences were recorded at various intervals during a discharge from the double impaled fibres. A typical recording obtained by this technique is shown in Fig. 1. The spontaneous fibrillation potential can be recognized by the slow depolarization leading to the spike, whereas the propagated potential rises suddenly from the resting line. The rate of propagation, calculated from the latency between the fibrillating and the propagated spikes, attained an average value of $2.07 \pm$ $0.70 \mathrm{~m} / \mathrm{sec}$ (44 fibres out of 10 denervated muscles).

The recordings shown in Fig. 1 were taken during the initiation (A), the middle part (B) and the end (C) of a discharge that lasted $90 \mathrm{sec}$. It can be seen in $C$ that even though the size of the fibrillating potential decreased to about one-third of its initial height, it was still followed by a full size propagated action potential.
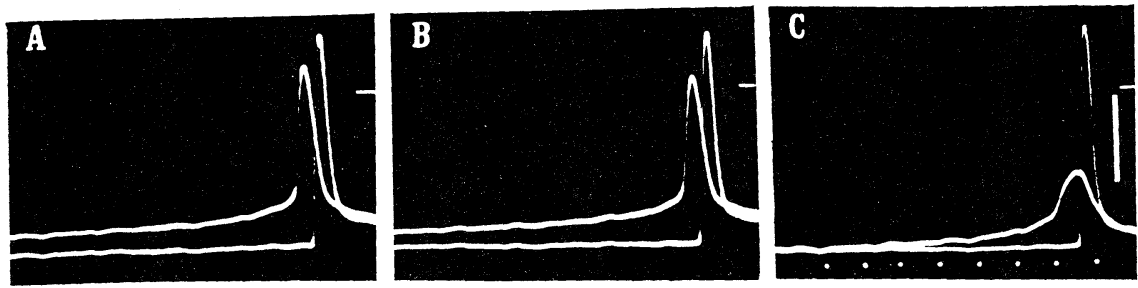

Fig. 1. Fibrillation potentials and propagated spikes. Action potentials recorded from two points of a muscle fibre 18 days after denervation. The fibrillation potential, recognizable by the slow depolarization preceding the spike, gives rise to a propagated action potential which rises suddenly from the resting line. The recordings were taken at the beginning (A), the middle part (B), and the end (C), of a discharge that lasted $90 \mathrm{sec}$. The amplitude of the spontaneous potential, as well as the rate of conduction for the propagated spike progressively diminished throughout the discharge. Conduction velocity, $1.99 \mathrm{~m} / \mathrm{sec}$ in $\mathrm{A}$ and $1.63 \mathrm{~m} / \mathrm{sec}$ in C. Distance between the two recording microelectrodes, $4.2 \mathrm{~mm}$. The marks on the left edge indicate zero potential. The upstroke of the action potential was slightly retouched to increase contrast. Calibrations: $40 \mathrm{mV}$ and $5 \mathrm{msec}$ intervals. 

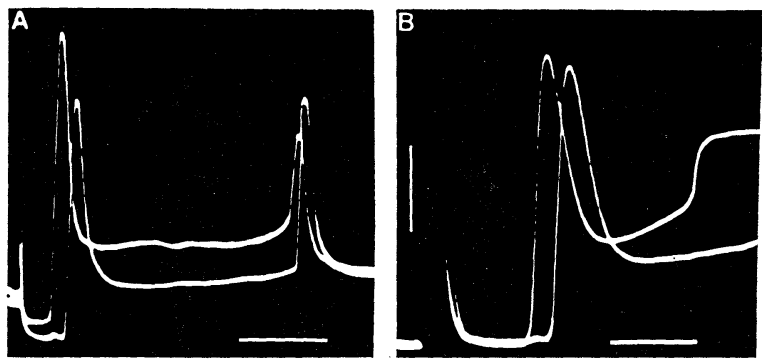

Fig. 2. Spikes evoked by electrical stimulation, recorded at two distances from the stimulation point. A: recordings from a denervated fibre 40 days after denervation. The evoked spike was followed by a discharge of fibrillation potentials. Rates of propagation: $1.65 \mathrm{~m} / \mathrm{sec}$ for the electrically evoked spike; $3.40 \mathrm{~m} / \mathrm{sec}$ for the spike generated by fibrillation activity. Distance between the two recording microelectrodes, $2.76 \mathrm{~mm}$. B: recordings from an innervated fibre; rate of propagation, $2.65 \mathrm{~m} / \mathrm{sec}$; distance between the microelectrodes, $2.7 \mathrm{~mm}$. The upstroke of the action potentials slightly retouched to increase contrast. Calibrations: horizontal, $10 \mathrm{msec}$ in A, $5 \mathrm{msec}$ in B; vertical, $40 \mathrm{mV}$.

The propagated activity like the one shown in Fig. 1 ended either when the small spontaneous potential ceased abruptly, or when these potentials were replaced by the small rhythmic oscillations described in a previous paper (LOPEZ, 1978).

Another finding in this relation was a decrease of the rate of conduction observed during the progression of a fibrillatory discharge. Thus, for the recordings shown in Fig. 1, the rate of conduction declined from $1.99 \mathrm{~m} / \mathrm{sec}$ in A, to $1.63 \mathrm{~m} / \mathrm{sec}$ in $\mathrm{C}(82 \%$ of the starting speed) at the end of the fibrillatory firing.

The rate at which an spike evoked by an electric pulse is conducted along a denervated fibre was also calculated. An average value of $2.13 \pm 0.76 \mathrm{~m} / \mathrm{sec}$ was obtained for this conduction ( 8 fibres out of 4 denervated muscles).

It was also observed in some denervated fibres that the spike evoked by a threshold electric pulse was followed on occasion by a discharge of fibrillation potentials. The initial rate of propagation for the discharge thus aroused was faster, up to $100 \%$, than the rate of propagation for the preceding evoked action potential. This finding is illustrated in Fig. 2A, in which the evoked spike propagated at a rate of $1.65 \mathrm{~m} / \mathrm{sec}$, while the speed for the subsequent couple of fibrillation potentials was $3.40 \mathrm{~m} / \mathrm{sec}$.

\section{Propagation in innervated fibres}

The rate at which impulses are conducted by innervated fibres was also studied in fibres belonging to muscles contralateral to the denervated ones. An average value of $2.14 \pm 0.68 \mathrm{~m} / \mathrm{sec}$ was found for the propagation in these fibres (30 fibres out of 5 muscles). In most of these experiments one and even both of the microelectrodes were ejected from the cell as a consequence of the mechanical response (Fig. 2B). It is worth mentioning that ejection of the microelectrodes, as a consequence of the response to the electrical stimulation, was rarely observed in dener- 
vated flbres.

\section{Tension development}

Tension development by denervated fibres. Single twitch fibres were dissected out of denervated muscles to be used in studying their ability to produce tension. It was observed, in this relation, that although the surgical approach to denervate the semitendinosus avoided the close vicinity to the muscle, proliferation of connective tissue was a routine finding, mainly in the neighborhood of the nerve entrance into the muscle. This condition made isolation of single fibres an extremely difficult procedure. Thus, the 12 single denervated fibres used for this part of the study were only partially isolated. Starting with a thin bundle containing from 10 to 20 fibres, elements were stripped off, in a length of 3-7 mm, at one of the ends of the bundle until only one fibre was left. The rest of the length of the chosen fibre remained surrounded by the debris of the cut elements. The diameter of the fibres varied in range from 30 to $110 \mu \mathrm{m}$. The average twitch tension developed by them was $3.20 \pm 1.46 \mathrm{~kg} / \mathrm{cm}^{2}$ within a range of 0.962 to $5.58 \mathrm{~kg} / \mathrm{cm}^{2}$.

Tension development by innervated fibres. Twitch tension was also studied in single fibres dissected out, tendon to tendon, from the contralateral innervated semitendinosus ( 5 fibres varying in diameter from 40 to $120 \mu \mathrm{m}$, out of 5 muscles). The average twitch tension developed by these fibres was $3.30 \mathrm{~kg} / \mathrm{cm}^{2}$ with extreme values of 5.91 and $1.53 \mathrm{~kg} / \mathrm{cm}^{2}$.

It seems worth mentioning that the average values reported here, both for denervated and innervated fibres, are similar to the values calculated for single fibres stimulated at a rate of 125/sec (HoDGKIN and Horowicz, 1960).

\section{Effects of manganese ions}

Manganese ions and fibrillation potentials. Addition of manganese ions to the Ringer saline bathing a denervated muscle rendered the fibres unable to discharge fibrillation potentials.

Initially the experiments were made on the whole ventral body of the denervated muscle. It was observed that some of the fibres studied lost the ability to discharge fibrillation potentials after immersion in $1 \mathrm{~mm}$ manganese saline. However, the inhibitory effects appeared earlier and extended to the whole population of fibres studied, when the $3 \mathrm{~mm}$ manganese saline was used. Thus, the latter concentration was used in all subsequent experiments. The inability to discharge spontaneously lasted as long as the muscle remained immersed in the $\mathrm{Mn}$ saline (up to $30 \mathrm{~min}$ ) and reappeared within $1 \mathrm{~min}$ after the removal of manganese.

Further information about manganese effects was obtained from experiments on muscle strips containing a small number of denervated fibres. Simultaneous recordings of potential and tension were obtained from these experiments. Addition of manganese during a discharge of fibrillation potentials lead to abolition of the fibrillatory activity within 10-20 sec. After the cessation of the discharge the 
membrane repolarized to a level close to the average resting potential $(85 \mathrm{mV})$. Inhibition of fibrillation potentials was maintained as long as the fibres remained immersed in the manganese saline. On the other hand, action potentials of normal appearance could be evoked by electrical stimulation of the strip during the exposure to $\mathrm{Mn}^{2+}$. On removal of $\mathrm{Mn}^{2+}$ the membrane depolarized progressively to a level at which the discharge of fibrillation potentials started again. These findings are illustrated by the recordings shown in Fig. 3.

Manganese ions and resting tension. $\mathrm{Mn}^{2+}$ also affected the tension induced by stretching the denervated fibres beyond their slack length (resting tension). As it shown by the tension record in Fig. 3 (upper trace), the fibres started to loose tension even at a time when the muscle was still firing fibrillation potentials; $i$. e., manganese ions inhibited the small amount of tension developed during a fibrillatory discharge. The inhibition of tension followed a time course slower than that for the abolition of fibrillation potentials, and went on until no resting tension subsisted. After the removal of manganese, resting tension started to reappear and increased slowly towards the pre-manganese level; the control value was reached in $10-15 \mathrm{~min}$.

Inhibition of tension was also observed in strips in which the resting tension was diminished by loosing the strip to 1.05-1.1 the slack length. The recordings shown in Fig. 4 were taken from a strip exposed twice to $3 \mathrm{~mm}$ manganese saline. The effects produced during the first exposure were similar to those illustrated in Fig. 3. Ten minutes later the resting tension was diminished by decreasing the

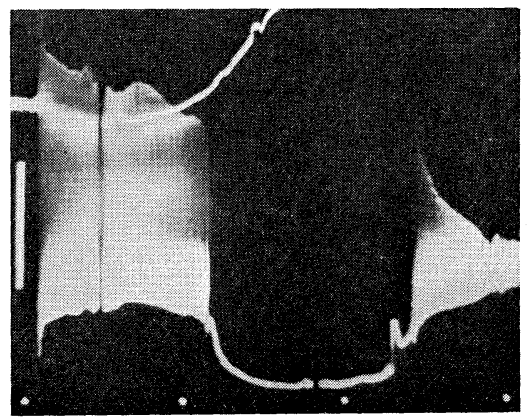

Fig. 3. Inhibitory effects of manganese on fibrillation potentials and tension. Strip of fibres denervated 18 days previous to the experiment. Simultaneous recordings of tension (upper trace) and electrical activity. Tension trace superimposed on the electrical recording beam (zero potential) at the left of the figure. A discharge of fibrillation potentials was triggered by penetration of the microelectrode; the preparation was then exposed to $3 \mathrm{~mm} \mathrm{Mn}$ (interval between the interruptions of the potential trace). $\mathrm{Mn}^{2+}$ abolished fibrillation potentials and repolarized the membrane to a value about the average resting potential. The small amount of tension developed during fibrillation, as well as the resting tension, were also inhibited; tension record went out of screen. Fibrillation potentials reappeared within $10 \mathrm{sec}$ after removal of $\mathrm{Mn}^{2+}$, recovery of twitch and resting tensions took more than $12 \mathrm{~min}$. Calibrations: $40 \mathrm{mV}$ and $60 \mathrm{mg} ; 20 \mathrm{sec}$ intervals. 


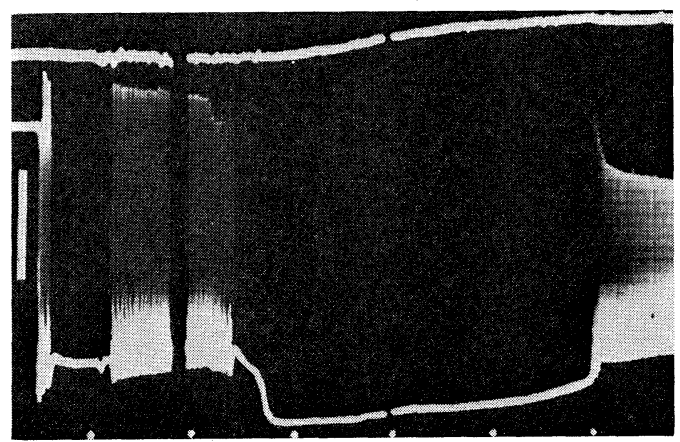

Fig. 4. Inhibitory effects of manganese upon a strip stretched to 1.07 the slack length. Recordings obtained 18 days after denervation. This preparation was exposed previously to $3 \mathrm{~mm}$ manganese saline, while stretched to 1.2 the slack length. Ten min after recovery stretch was reduced to 1.07 the slack length and the strip exposed again to manganese (interval between interruptions of the traces). The effects are similar to those shown in Fig. 3. Tension amplification reduced to show the whole range of inhibition. Calibrations: $40 \mathrm{mV}$ and $200 \mathrm{mg}$; $10 \mathrm{sec}$ intervals.

stretch to 1.07 the slack length (upper trace displaced upwards in relation to the zero potential); manganese ions were then added for a second time to the saline. As during the first exposure, when the strip was submitted to a greater stretch, the fibrillating discharges as well as the resting tension were inhibited again by the cation.

Manganese ions and twitching activity. The effects of manganese ions on muscle tension were studied further in rhythmically twitching strips. The recordings shown in Fig. 5 illustrate a typical result. Although denervated fibres maintain their ability to twitch while exposed to manganese, a decrease in twitch tension was observed during the phase at which resting tension was diminishing. In some fibres the twitch tension went down to about $50 \%$ of the control value. Inhibition of twitch tension, however, was a transient effect followed by a period of recovery which attained control values while the strip was still immersed in manganese. After the removal of the cation, during the early recovery of resting tension, the tension developed by the twitches surpassed the control value, even though the corresponding resting tension remained well below the control level. This was also a transient effect; pre-manganese levels were attained within 10-15 min. A similar inhibitory effect of manganese ions on contractile responses has been reported for the skeletal muscles of the frog (Oota et al., 1972; CHIARANDINI and StefANI, (1973) and for the isolated frog atrial trabeculae (CHAPMAN and OCHI, 1971).

The effects of $\mathrm{Mn}^{2+}$ on resting tension in the nonstimulated strip were similar to those in the twitching preparation. It appeared, however, that the loss of tension developed faster than in twitching strips. This observation is illustrated by the lower set of records in Fig. 5. In this particular experiment a certain amount of 


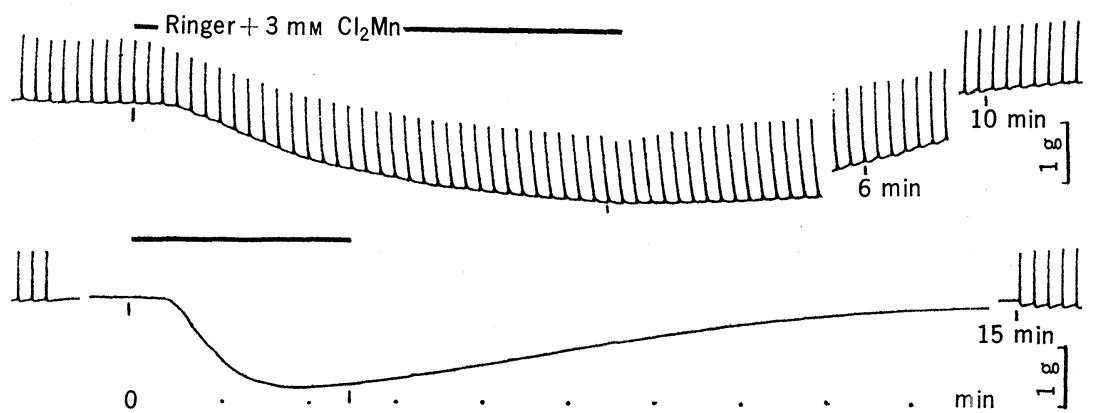

Fig. 5. Inhibitory effects of manganese on twitching activity and resting tension. Ink recordings from 2 denervated strips exposed to $3 \mathrm{~mm}$ Mn saline between the marks: strips dissected from the site of entrance of the nerve into the muscle. Upper records from a strip stimulated at $6 \mathrm{~min}^{-1}$. Twitch tension was transiently inhibited to about $85 \%$ of the control at the beginning of the exposure; complete recovery occurred while the strip was still in manganese. After removal of the cation a second transient was observed during which twitch tension surpassed the control value; recovery to control values occurred 10 min later. Lower records: stimulation was suspended 10 min prior to $\mathrm{Mn}^{2+}$ and restarted 15 min after removal of the $\mathrm{Mn}^{2+}$. $\mathrm{Mn}^{2+}$ effect on resting tension developed on a faster time course. Time after denervation 23 days for the upper strip; 26 days for the lower strip.

recovery could be observed even while the strip was still immersed in Mn saline. Reversal to the control level of resting tension occurred at intervals comparable to those observed for the recovery in twitching strips.

Effects of $\mathrm{Mn}^{2+}$ ions on muscle tension of innervated strips. The effects of manganese upon resting and twitch tension were also studied in innervated fibres. Initially the strips were dissected out from fascicles located at the site of entrance of the nerve, in the contralateral innervated ventral head. The effects, in general, were similar to those provoked by manganese ions in denervated preparations (records in Fig. 5). Certain differences were observed, however, concerning the degree of twitch tension inhibition. Twitch tension was inhibited to a greater extent (to about $40 \%$ of the control value), and no trend to recovery was observed while the fibres remained immersed in manganese saline.

On this account, strips were dissected out from a region of the muscle head located far apart and mid-ventrally in relation to the site of entrance of the nerve. Addition of manganese to the strips thus obtained inhibited twitch tension alone, leaving unaffected the level of resting tension. These results are illustrated by the upper set of records in Fig. 6.

To complete this series of experiments, strips dissected out from a comparable region of denervated muscles, i.e., far apart and mid-ventrally in relation to the site of entrance of the nerve, were exposed to manganese ions. The results were similar to those obtained with innervated strips; that is, twitch tension declined to about $40 \%$, while no effect upon resting tension could be registered. Some differ- 


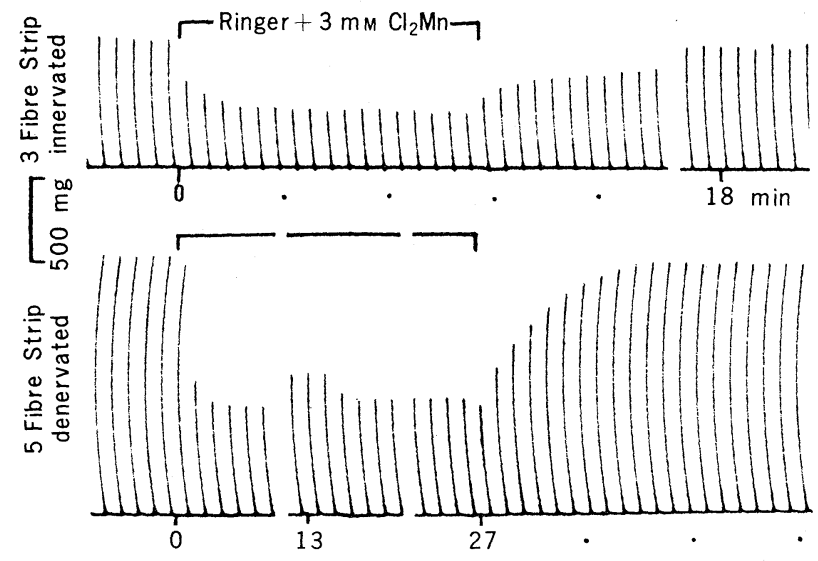

Fig. 6. Inhibitory effects of manganese on twitching activity of fibres not belonging to the region around the entrance of the nerve. Both strips were dissected from comparable zones of the muscles: areas located distantly and mid-ventrally in relation to the nerve entrance. Exposure to manganese (interval between the marks) inhibited twitch tension (up to $40 \%$ ), though no effect was observed on resting tension. The partial recovery of twitch tension observed in the denervated strip was reversed by adding fresh Mn saline (at minute 13). After removal of manganese recovery occurred faster in the denervated strip.

ences, however, could be appreciated: a certain degree of twitch tension recovery appeared during the exposure to manganese ions; the partial recovery was reversed by replacing fresh $\mathrm{Mn}$ saline in the channel. On the other hand, the after-manganese recovery occurred earlier than in innervated strips. These results are illustrated by the lower set of records in Fig. 6.

\section{Effects of glycerol}

Glycerol and fibrillation potentials. Whole denervated muscles and strips of denervated fibres were exposed to a saline made hypertonic by the addition of $400 \mathrm{~mm}$ of glycerol; the preparations were kept in the glycerolated saline from 60 to $65 \mathrm{~min}$ and then replaced into normal Ringer saline (HowELL and JENDEN, 1967). The denervated fibres maintained their ability to generate fibrillation potentials during the whole period of immersion in the hypertonic saline. Discharges of fibrillation potentials could be registered at different times (1-60 min) during the immersion in glycerol. On the other hand, after removal of glycerol, denervated fibres still maintained their ability to discharge fibrillation potentials for periods as long as $82 \mathrm{~min}$ after reimmersion in normal Ringer saline. The recordings in Fig. 7 illustrate the ability of denervated fibres to generate fibrillation potentials during and after the exposure to glycerol.

It was observed, however, that as the time after reimmersion in Ringer increased, the number of fibres from which fibrillation potentials could be recorded de- 


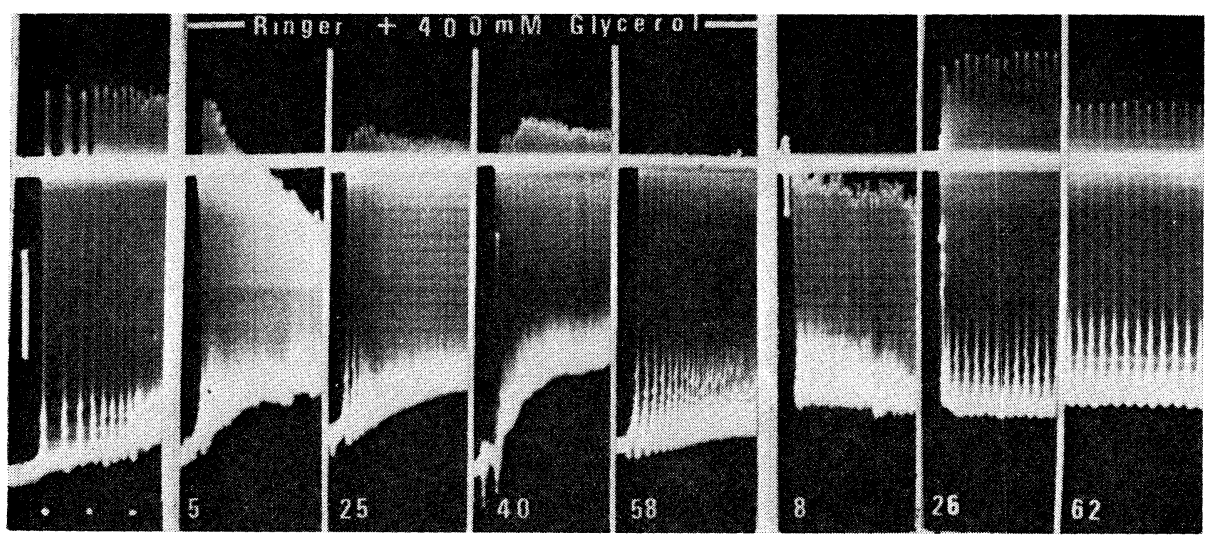

Fig. 7. Fibrillation potentials recorded during and after the exposure to a glycerol hypertonic saline. Recordings obtained from the surface fibres of the ventral body 42 days after denervation. Fibrillation potentials prior to glycerol exposure are shown by the picture at the extreme left. The muscle was immersed in $400 \mathrm{~mm}$ glycerol saline during 60 min; fibrillation discharges were recorded at minute 5, 25, 40 and 58, after immersion. The fibrillation discharges shown in the last three pictures to the right were recorded at minute 8, 26 and 62 after reimmersion in Ringer saline. Calibrations: $40 \mathrm{mV}$ and $10 \mathrm{sec}$ intervals.

creased. The membrane potential of the fibres which did not fire was found to be at or more positive to $60 \mathrm{mV}$. This finding is in agreement with previous observations, according to which the membrane of muscle fibres exposed to hypertonic glycerol treatment depolarize progressively after reimmersion in normal Ringer (López, unpublished).

Glycerol and mechanical responses. The effects of glycerol on the mechanical responses of denervated muscles were studied in strips and single fibres. As described above, only a short length $(3-5 \mathrm{~mm})$ at either one of the ends of denervated fibres was isolated. Twitch responses were elicited by electric pulses applied at $6 / \mathrm{min}$. Immersion in the hypertonic saline affected the mechanical responses in the following way: a contracture-like development of tension occurred as soon as glycerol was added; twitch responses were abolished during the contracture. The glycrol contracture lasted up to $2 \mathrm{~min}$; the time to peak tension was, in general, shorter than the time for relaxation; the peak tension attained varied from 0.5 to 2 times the twitch tension. Twitch responses reappeared at the end of the contracture and twitch tension increased gradually until the maximal recovery was reached at about $30 \mathrm{~min}$ after immersion in glycerol; the degree of recovery varied from 0.5 to 1.5 the control tension. Twitch tension decreased again at the end of the $60 \mathrm{~min}$ period of immersion. In agreement with data reported in the literature (Howell and Jenden, 1967; Gage and Eisenberg, 1967; Caputo, 1968) twitch responses were permanently abolished after replacing the preparations in Ringer saline. 


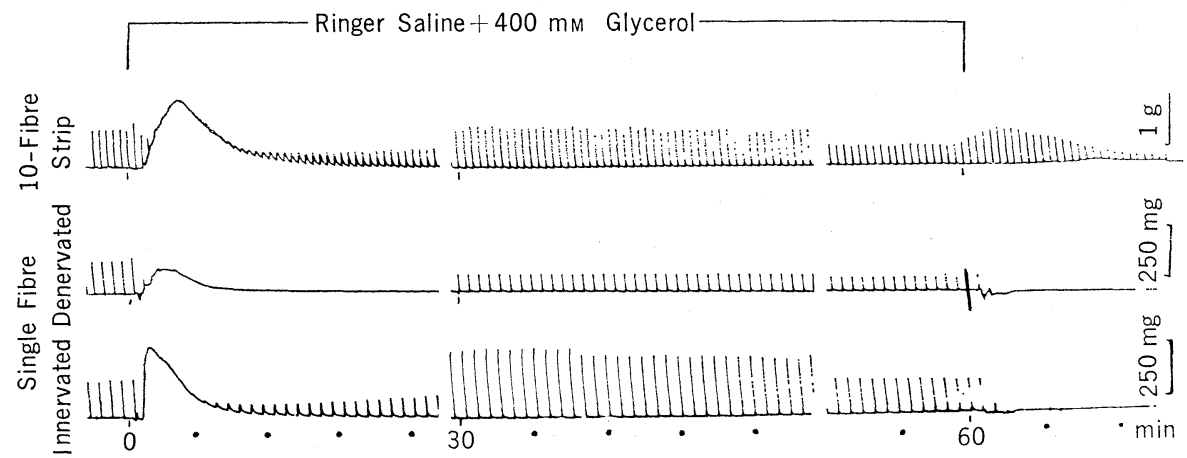

Fig. 8. Effects of glycerol hypertonic saline on the mechanical activity of muscle fibres. Preparations electrically stimulated at $10 \mathrm{~min}^{-1}$ (strip), and $6 \mathrm{~min}^{-1}$ (single fibres). Mechanical activity was similarly affected in the three preparations shown. Addition of glycerol provoked a contracture-like development of tension and the transient abolition of twitching. Twitch responses reappeared at the end of the contracture and twitch tension increased gradually until a maximal recovery was reached at about 30 min after addition of glycerol. Twitch tension decreased again at the end of the period of immersion. Twitches were permanently abolished after reimmersion in Ringer saline. Diameters of the single fibres: denervated, $60 \mu \mathrm{m}$; innervated, $120 \mu \mathrm{m}$. Tension per unit area in Ringer saline: denervated fibre, $5.47 \mathrm{~kg} / \mathrm{cm}^{2}$; innervated fibre, $3.14 \mathrm{~kg} / \mathrm{cm}^{2}$. Time after denervation: strip, 16 days; single fibre, 29 days.

Similar results were obtained with single fibres, isolated from tendon to tendon, from innervated muscles. The results described are illustrated by the set of traces shown in Fig. 8.

\section{DISCUSSION}

The experimental results described in this paper show that the electrical fibrillatory activity observed in denervated muscles gives rise to propagated action potentials. The average conduction velocity for the propagated potentials is similar in both the innervated and the denervated muscle membranes and comparable to the values reported in the literature (HAKANSSON, 1956; HoDGKIN and NAKAJIMA, 1972b) for frog normal muscle fibres. It is interesting to note that even though the progressive diminution of the fibrillatory spontaneous potentials propagated spikes were still aroused by fibrillation potentials of about $20 \mathrm{mV}$. This value is lower than those reported in the literature for the spike-producing potential at the end plate region by nerve stimulation (FATT and KATZ, 1951; KUFFLER, 1942) and at the nerve-free portion of the membrane by direct stimulation (FATT and KATZ, 1951). It appears possible from these observations that the critical potential difference between adjacent parts of the membrane required for propagation is lower in the denervated than in the innervated muscle. This possibility is in agreement with experimental data showing that denervation provokes an increase in 
the membrane resistance of frog muscles (NICHOLLS, 1956).

It has been shown in this study that the twitch tension developed by denervated fibres is comparable to the values reported in the literature for single fibres stimulated at 125/sec (HoDGKIN and Horowicz, 1960). The average value reported here $\left(3.97 \mathrm{~kg} / \mathrm{cm}^{2}\right)$, might be the result of an unknown amount of stretch exerted upon the intact single fibre by the surrounding debris and connective tissue left during the dissection procedure. This stretch summated to that due to the initial elongation to 1.2 the slack length, might have shifted the starting level for a twitch towards the optimal point (HuxLeY and PeACHY, 1961) along the length tension diagram (RAMSEY and STREET, 1940). Another explanation allows for a possible error in the calculation of cross-sectional areas. Since diameter measurements were made on one point, at one end of the fibres, it is possible that this method may have underestimated surface area (HoDGKIN and NAKAJIMA, 1972a). It is possible, however, on account of the results obtained with single innervated fibres isolated from tendon to tendon, that the average tension reported in this paper corresponds to the actual output of twitch tension for the local frog.

It has been postulated that the mechanism underlying the origin of the fibrillation potentials might be similar to the regenerative change in $\mathrm{Na}$ conductance associated with the normal action potential, although on a much slower time base (Purves and Sakmann, 1974; Smith and TheslefF, 1976). The results presented in this paper show that $\mathrm{Mn}$ ions selectively block the production of fibrillation potentials while they leave unaffected the evoked propagated spike. This finding suggests that a mechanism not entirely similar to that for the propagated action potential might be responsible for the production of fibrillation potentials.

Recent investigations on the mechanisms underlying the action potential of heart tissues have lead to the separation of the total inward current in two components (ROUGIER et al., 1969; TARR, 1971). A fast inward current, which accounts for the rapid phase of the upstroke of the action potential; and a slow inward current responsible for the slow phase of depolarization and the plateau of myocardial action potentials (CARMELIET and VEREECKE, 1969; BEELER and REUTER, 1970). The fast inward current is carried by sodium ions (Rougrer et al., 1969; TARR, 1971), through specific pores called fast sodium channels (BENZER and RAFTery, 1972; Hille, 1971; Keynes et al., 1971; NARAHAShI, 1972), and it can be selectively blocked in the heart by TTX (Dudel et al., 1967). The slow inward current is carried by sodium and/or calcium ions (BEELER and REUTER, 1970; NEW and Trautwein, 1972; OCHI, 1970) through a different set of pores called slow channels (ROUGIER et al., 1969), and it is selectively blocked by manganese (CorABOEUF and VASSORT, 1968; Hagiwara and NAKAJIMA, 1966). In addition it has been shown that manganese ions competitively inhibit the Ca-spike of the barnacle muscle fibre (HAGIWARA and NAKAJIMA, 1966). In this relation, a delayed calcium dependent spike has been recently described in frog muscle fibres (BEATY and Stefani, 1976). Voltage clamp experiments have shown that by reducing potas- 
sium and chloride conductances a slow inward current can be detected in frog skeletal muscle fibres (STANFIELd, 1977; SÁnChez and Stefani, 1978). This slow inward current is carried by calcium ions, perhaps through a specific set of channels; it is not affected by tetrodotoxin and it appears to be the membrane current underlying the delayed calcium spike (SÁnCHeZ and STEFani, 1978). On the other hand, experimental results have demonstrated that denervation may alter some of the basic properties of muscle membranes. Thus, the ionic permeability (HARris and NiCHOLls, 1956; Kernan and MCCHARTY, 1972) the sensitivity to acetylcholine (MILEDI, 1960) and the electric characteristics (NiCHOLLS, 1956) of denervated muscles have been found to be different from those in innervated muscles.

On these grounds it seems reasonable to assume, as a possible explanation, that the prepotentials and the fibrillation potentials observed in frog denervated muscles might be generated by a mechanism in which a slow inward current is the main factor. The corresponding set of slow channels, possibly existant and functional at an early stage of muscle development (KonIGSBERG, 1960; Li et al., 1959; CAPERS, 1959), might be unmasked and reopened as a consequence of the alterations produced on the membrane by denervation.

The repolarization observed after the inhibition of fibrillation potentials in fibres exposed to $3 \mathrm{~mm} \mathrm{Mn}$ may be equivalent to the hyperpolarization observed in frog muscles exposed for $30 \mathrm{~min}$ to $10-20 \mathrm{~mm} \mathrm{Mn}$. The latter effect has been attributed to a reduction of the resting permeability to Na (CHIARANDINI and STEFANI, 1973). It is worth to mention here that even though no microscopical change was observed in the Ringer after the addition of $\mathrm{MnCl}_{2}$, some precipitate might have occurred thus reducing the $3 \mathrm{~mm}$ Mn concentration.

The partial inhibition of the twitch responses produced by $\mathrm{Mn}^{2+}$ may tentatively be attributed to a possible inhibitory effect of manganese on the coupling mechanism related, perhaps, to the amount of $\mathrm{Ca}^{2+}$ available for activation of the contractile elements. A similar explanation has been proposed for the inhibitory effects of manganese on the tension developed by frog and crayfish muscle fibres (Chiarandini and SteFAni, 1973; OrKand, 1962.)

The effects of manganese upon resting tension, as well as the fact that fibrillation potentials can be consistently recorded only from a certain bundle of fibres of the semitendinosus, suggest that the functional characteristics of frog twitch muscle cells may not be the same for the whole population of twitch fibres. Fibres in the neighborhood of the nerve entrance being the most susceptible to generate fibrillation potentials, and the only ones in which the resting tension is affected by manganese.

The present study shows that in the frog, contrarilly to what has been observed in the mouse (SMITH and THESLEFF, 1976), fibrillation potentials can be registered along the whole length of the fibre after exposure to glycerol. According to quantitative observations (EISENBERG and EISENBERG, 1968) glycerol treatment destroys 
most of the transverse tubular system present in muscle fibres. Thus, it appears that in the frog, the generation of fibrillation potentials is a characteristic of the external denervated membrane, rather than a function of the transverse system of tubes (Purves and SaKmanN, 1974; SMITH and TheslefF, 1976).

The effects of hypertonic salines on the contractile responses of innervated muscle fibres have been attributed to a break of the link between excitation and contraction (SANDOW, 1965; CAPUTO, 1968) and to changes in viscosity (HowARTH, 1958) and ionic strength (HowArTH, 1958; AprIL et al., 1968) provoked by the movement of water into and out of the cells. Since denervation does not appreciably modify the effect on the twitch responses of fibres exposed to glycerol, in relation to the same effects produced by hypertonic solutions in innervated fibres (Fuino et al., 1961; Caputo, 1968; Hodgkin and Horowicz, 1957; Howarth, 1958; YAMAGUCHI et al., 1962), it seems likely that the above-mentioned mechanisms may also explain the transient inhibition reported here. The permanent abolition of the twitch responses observed after reimmersion in normal Ringer may be attributed to the disconnection from the surface of the transverse tubular system provoked by the glycerol treatment (HowELL and JENDEN, 1967; GAGE and EISENBERG, 1967).

In conclusion, the fibrillation potentials generated by denervated muscle fibres of frog semitendinosus, give rise to propagated spikes similar to those evoked by an electric pulse. The rate of propagation being alike to that measured in innervated fibres. Exposure to $\mathrm{Mn}^{2+}$ reversibly abolishes fibrillation potentials. Fibrillatory discharges can still be registered after an osmotic shock provoked by glycerol treatment. The twitch tension developed in response to electrical stimulation is alike in both, denervated and innervated fibres. On these bases no explanation can be offered for the poor or none tension developed during a discharge of fibrillation potentials.

\section{REFERENCES}

April, E., Brandt, P. W., Reuben, J. P., and Grundfest, H. (1968) Muscle contraction: The effect of ionic strength. Nature, 220: 182-184.

Beaty, G. N. and Stefani, E. (1976) Calcium dependent electrical activity in twitch muscle fibres of the frog. Proc. R. Soc., Ser. B, 194: 141-150.

BeEler, G. W. and Reuter, H. (1970). Membrane calcium current in ventricular myocardial fibers. J. Physiol. (Lond.), 207: 191-209.

Benzer, T. I. and RAFTERY, M. A. (1972) Partial characterization of a tetrodotoxin-binding component from nerve membrane. Proc. Natl. Acad. Sci. U.S.A., 69: 3634-3637.

CAPERS, C. R. (1959) Multinucleation of skeletal muscle in vitro. J. Biophys. Biochem. Cytol., 7: $559-565$.

Caputo, C. (1968) Volume and twitch tension changes in single muscle fibers in hypertonic solutions. J. Gen. Physiol., 52: 793-809.

CARMeliet, E. and VereEcke, J. (1969) Adrenaline and the plateau phase of the cardiac action potential. Pflügers Arch., 313: 300-315.

Chapman, R. A. and OcHI, R. (1971) The effects of manganese ions on the contractile re- 
sponses of isolated frog atrial trabeculae. J. Physiol. (Lond.), 222: 56P-58P.

Chiarandini, D. J. and Stefani, E. (1973) Effects of manganese on the electrical and mechanical properties of frog skeletal muscle fibers. J. Physiol. (Lond.), 232: 129-147.

CORABOEUF, E. and VASSORT, G. (1968) Effects of some inhibitors of ionic permeabilities on ventricular action potential and contraction of rat and guinea pig hearts. J. Electrocardiol., 1: 19-29.

Dudel, J., Peper, K., Rudel, R., and Trautwein, W. (1967) Effects of tetrodotoxine on membrane currents in mammalian cardiac fibres. Nature, 213: 296-297.

EISENBERG, B. and EISENBERG, R. S. (1968) Selective disruption of the sarcotubular system in frog sartorius muscle. J. Cell Biol., 39: 451-467.

FAtT, P. and KATz, B. (1951) An analysis of the end-plate potential recorded with an intracellular electrode. J. Physiol. (Lond.), 115: 320-370.

Fujino, M., Yamaguchi, T. and Suzuki, K. (1961) Glycerol effects and the mechanism linking excitation of the plasma membrane with contraction. Nature, 192: 1159-1161.

Gage, P. W. and Eisenberg, R. S. (1967) Action potential without contraction in frog skeletal muscle fibers with disrupted transverse tubules. Science, 158: 1702-1703.

Hagiwara, S. and NaKaJima, S. (1966) Differences in $\mathrm{Na}$ and Ca spikes as examined by application of tetrodotoxin, procaine and manganese ions. J. Gen. Physiol., 49: 793-806.

HAKANSSON, C. H. (1956) Conduction velocity and amplitude of the action potential as related to circumference in the isolated fibre of frog muscle. Acta Physiol. Scand., 37: 14-34.

Harris, E. J. and Nicholls, J. G. (1956) The effect of denervation on the rate of entry of potassium into frog muscle. J. Physiol. (Lond.), 131: 473-476.

Hille, B. (1971) The permeability of the sodium channel to organic cations in myelinated nerve. J. Gen. Physiol., 58: 599-619.

Hodgkin, A. L. and Horowicz, P. (1957) The differential action of hypertonic solutions on the twitch and action potential of a muscle fibre. J. Physiol. (Lond.), 136: 17P-18P.

Hodgkin, A. L. and Horowicz, P. (1960) Potassium contractures in single muscle fibres. $J$. Physiol. (Lond.), 153: 386-403.

Hodgkin, A. L. and NaKajima, S. (1972a) The effect of diameter on the electrical constants of frog skeletal muscle fibres. J. Physiol. (Lond.), 221: 105-120.

Hodgkin, A. L. and NaKaJima, S. (1972b) Analysis of the membrane capacity in frog muscle. J. Physiol. (Lond.), 221 : 121-136.

Howarth, J. V. (1958) The behavior of frog muscle in hypertonic solutions. J. Physiol. (Lond.), 144: 167-175.

Howell, J. N. and Jenden, D. J. (1967) T tubules of skeletal muscle: Morphological alterations which interrupt excitation contraction coupling. Fed. Proc., 26: 553 (abstr. 1963).

HuXley, A. F. and PeACHY, L. D. (1961) The maximum length for contraction in vertebrate striated muscle. J. Physiol. (Lond.), 156: 150-165.

Kernan, R. P. and MCCharty, I. (1972) Effects of denervation on ${ }^{42} \mathrm{~K}$ influx and membrane potential of rat soleus measured in vivo. J. Physiol. (Lond.), 226: 62P-63P.

Keynes, R., Ritchie, J., and Rojas, E. (1971) The binding of tetrodotoxin to nerve membranes. J. Physiol. (Lond.), 213: 235-254.

KonigsberG, I. R. (1960) The differentation of cross-striated myoflbrils in short term cell culture. Exp. Cell Res., 21: 414-420.

KUFFLER, S. W. (1942) Electric potential changes at an isolated nerve-muscle junction. J. Neurophysiol., 5: 18-26.

LI, C., Engel, K., and Klatzo, I. (1959) Some properties of cultured chick skeletal muscle with particular reference to fibrillation potential. J. Cell. Comp. Physiol., 53: 421-444.

LópEz, E. (1978) Electrical and mechanical activities in the denervated semitendinosus muscle of the frog. Jpn. J. Physiol., 28: 401-412.

Vol. 29, No. 6, 1979 
Miledi, R. (1960) The acetylcholine sensitivity of frog muscle fibres after complete or partial denervation. J. Physiol. (Lond.), 151: 1-23.

NARAHASHI, T. (1972) Mechanism of action of tetrodotoxin and saxitonin on excitable membranes. Fed. Proc., 31 : 1124-1132.

New, W. and Trautwein, W. (1972) The ionic nature of the slow inward current and its relation to contraction. Pflügers Arch., 334: 24-38.

Nicholls, J. G. (1956) The electrical properties of denervated skeletal muscle. J. Physiol. (Lond.), 131: 1-12.

OCHI, R. (1970) The slow inward current and the action of manganese ions in guinea-pig's myocardium. Pflügers Arch., 316: 81-94.

Oota, I., TAKauj, M., and Nagai, T. (1972) Effect of manganese on excitation-contraction coupling in frog sartorius muscles. Jpn. J. Physiol., 22: 379-392.

ORKAND, R. K. (1962) Chemical inhibition of contraction in directly stimulated crayfish muscle fibres. J. Physiol. (Lond.), 164: 103-115.

Purves, D. and SaKmanN, B. (1974) Membrane properties underlying spontaneous activity of denervated muscle fibres. J. Physiol. (Lond.), 239: 125-153.

Ramsey, R. W. and StreEt, S. F. (1940) The isometric length-tension diagram of isolated skeletal muscle fibres of the frog. J. Cell. Comp. Physiol., 15: 11-34.

Reuben, J. P., Girardier, L., and Grundfest, H. (1964) Water transfer and cell structure in isolated crayfish muscle fibres. J. Gen. Physiol., 47: 1141-1174.

Rougier, O., Vassort, G., Garnier, D., Gargouil, Y. M., and Coraboeuf, E. (1969) Existence and role of a slow inward current during the frog atrial action potential. Pflügers Arch., 308: 91-110.

SÁNChez, J. A. and Stefani, E. (1978) Inward calcium current in twitch muscle fibres of the frog. J. Physiol. (Lond.), 283: 197-209.

SANDOw, A. (1965) Excitation-contraction coupling in skeletal muscle. Pharmacol. Rev., 17: $265-320$.

SMITH, J. W. and TheSLEFF, S. (1976) Spontaneous activity in denervated mouse diaphragm muscle. J. Physiol. (Lond.), 257: 171-186.

StANField, P. R. (1977) A calcium dependent inward current in frog skeletal muscle fibres. Pflügers Arch., 368: 267-270.

TARr, M. (1971) Two inward currents in frog atrial muscle. J. Gen. Physiol., 58: 523-543.

Yamaguchi, T., Matsushima, T., Fujino, M., and Nagai, T. (1962) The excitation-contraction coupling of the skeletal muscle and the glycerol effect. Jpn. J. Physiol., 12: 129-152. 